
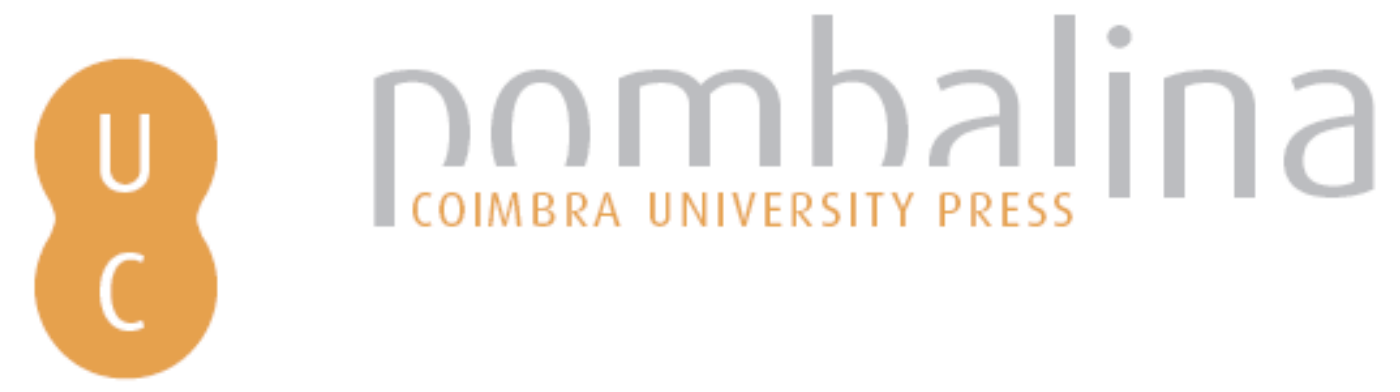

\title{
Patrimônio, discurso e prática: incursões sobre democracia e cidadania a partir do Rio de Janeiro e o patrimônio mundial
}

\author{
Autor(es): $\quad$ Ribeiro, Rafael Winter \\ Publicado por: Imprensa da Universidade de Coimbra \\ URL \\ persistente: URI:http://hdl.handle.net/10316.2/43433 \\ DOI: $\quad$ DOI:https://doi.org/10.14195/978-989-26-1475-5_4 \\ Accessed : $\quad$ 26-Apr-2023 12:13:27
}

A navegação consulta e descarregamento dos títulos inseridos nas Bibliotecas Digitais UC Digitalis, UC Pombalina e UC Impactum, pressupõem a aceitação plena e sem reservas dos Termos e Condições de Uso destas Bibliotecas Digitais, disponíveis em https://digitalis.uc.pt/pt-pt/termos.

Conforme exposto nos referidos Termos e Condições de Uso, o descarregamento de títulos de acesso restrito requer uma licença válida de autorização devendo o utilizador aceder ao(s) documento(s) a partir de um endereço de IP da instituição detentora da supramencionada licença.

Ao utilizador é apenas permitido o descarregamento para uso pessoal, pelo que o emprego do(s) título(s) descarregado(s) para outro fim, designadamente comercial, carece de autorização do respetivo autor ou editor da obra.

Na medida em que todas as obras da UC Digitalis se encontram protegidas pelo Código do Direito de Autor e Direitos Conexos e demais legislação aplicável, toda a cópia, parcial ou total, deste documento, nos casos em que é legalmente admitida, deverá conter ou fazer-se acompanhar por este aviso.

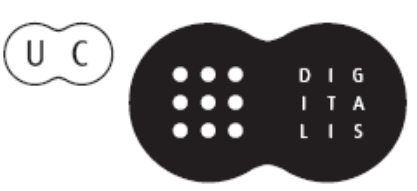


PATRIMÔNIO, DISCURSO E PRÁTICA:

INCURSÕES OBRE DEMOCRACIA E CIDADANIA

A PARTIR DO RIO DE JANEIRO E O PATRIMÔNIO MUNDIAL

DOI https://doi.org/10.14195/978-989-26-1475-5_4

Rafael Winter Ribeiro

As manifestações populares no Brasil que se iniciaram em junho de 2013, embora com caráter difuso e sem uma liderança clara, se possuem algo que as une, é a insatisfação generalizada com a política e com o fazer político. Deflagradas como protesto contra o aumento do preço das passagens e a violência policial, na pauta das manifestações entraram temas tão diversos como a melhoria da educação, saúde, saneamento básico; contra a corrupção, homofobia, gastos com a Copa do Mundo, entre tantos outros. Na verdade, o que estas manifestações revelavam naquele momento para aqueles que tentavam compreendê-las era a necessidade de um novo olhar sobre a cidadania e as instituições políticas. O que estava sendo colocado em debate era a própria democracia brasileira e as formas como a cidadania e a democracia podem e devem ser exercidas.

Mas o que essas manifestações podem nos dizer sobre patrimônio cultural na atualidade? O que podemos aprender com elas? Diante de pautas com temas tão mobilizadores do público em geral, como a preocupação com educação e saúde, há espaço para uma reflexão sobre patrimônio cultural? Logo esse tema, muitas vezes acusado de elitista, mercantilizado e turistificado?

Desde a gestão de Aloísio Magalhães no final dos anos 1970 e início dos anos 1980 no SPHAN/Pró-Memória fala-se sobre a necessidade de ouvir os sujeitos do patrimônio através da ideia de Referência Cultural, mas as instituições de patrimônio ainda encontram uma série de problemas no momento de por essas ideias na prática, ligados, muitas vezes, à própria estrutura das instituições. O objetivo aqui é discutir como pensar o patrimônio cultural em contextos democráticos e associados à prática da ci- 
dadania a partir de um ponto de vista da geografia política, em diálogo com diferentes campos. Se na atualidade cresce por parte dos geógrafos o interesse sobre o patrimônio cultural como objeto de investigação, outro tema historicamente negligenciado também não pode ser deixado de lado: a democracia. Ao falarmos de patrimônio estamos falando de uma forma de representação de identidades, de tempo e de espaço, que tem no território sua base material. A forma como essas representações em torno do patrimônio se constituem, as disputas e os instrumentos institucionais organizados e mobilizados na sua constituição são, portanto, o objeto de uma geografia política que se preocupa com as bases institucionais do fazer político e sua relação com território.

É nesse sentido que defendo aqui um olhar sobre o patrimônio cultural desde a geografia política. Isso significa olhar a prática de patrimonialização como uma ação eminentemente política, com uma base e rebatimentos significativos sobre o espaço. Se historicamente construído a partir de um discurso da memória, o patrimônio é, antes de mais nada, uma prática espacial, porque se dá sobre um contexto espacial determinado; mas também uma prática política, porque é uma seleção, um recorte, uma maneira de atuar sobre o mundo que implica também no direcionamento do comportamento esperado de outros indivíduos e grupos a partir de um embate e/ou convencimento. Quem tem legitimidade de dizer o que é patrimônio, para que e para quem? Essas não são questões recentes, elas pairam sobre as reflexões sobre patrimônio há algumas décadas, entretanto, sua relevância se torna maior na medida em que incorporamos a dimensão da democracia e da cidadania na discussão, mas, ao mesmo tempo, uma série de entraves institucionais mostram a dificuldade de por em prática discursos inclusivos.

Para entender alguns dos desafios da política de patrimônio hoje, o trabalho está dividido em duas partes. Na primeira parte analiso os deslocamentos discursivo e de objeto no campo do patrimônio: do patrimônio histórico e artístico ao patrimônio cultural, do patrimônio como expressão artística e histórica de um grupo e manifestação de uma identidade nacional, ao patrimônio como prática da cidadania e promotor do desenvolvimento sustentável. Não se trata aqui de fazer mais um histórico das políticas de patrimônio, mas compreender como a ideia das práticas da cidadania e da democracia são incluídas no discurso sobre as políticas de patrimônio. $\mathrm{Na}$ segunda parte, a partir das recentes ações na direção de inscrições de sítios e objetos localizados na cidade do Rio de Janeiro junto à Lista de Pa- 
trimônio Mundial - as paisagens da cidade e o Cais do Valongo ${ }^{7}$ - procuro fazer uma breve e incompleta, porque incompleto está o próprio processo, avaliação dos caminhos seguidos até agora no âmbito das políticas federais para o tema, identificando como esses discursos de cidadania e democracia estão sendo colocados em prática na identificação e na gestão do patrimônio.

Sem entrar aqui no debate entre as formas de democracia, representativa ou direta, o modelo político não prescinde de uma base institucional consolidada, com fundamentos espaciais que constituem parte de sua própria natureza (CASTRO, 2013). Trata-se de um modo institucionalizado de resolução de conflitos e a forma como as instituições se aparelham e o conjunto de discursos que as fundamentam é fundamental nesse processo. Assim, instituições, discurso e prática, nem sempre alinhados, são os objetos privilegiados desse trabalho.

EXTENSÕES E DISTENSÕES DO PATRIMÔNIO NA ATUALIDADE

Monumento, Patrimônio histórico, patrimônio histórico e artístico nacional, patrimônio cultural. São vários os adjetivos que encontramos acompanhando a palavra patrimônio. Para além de uma mera diferenciação semântica, essas acepções revelam concepções distintas daquilo que comporia o próprio campo do patrimônio e dos contextos nos quais estes termos são utilizados. Embora alguma preocupação com a guarda da memória e os objetos e práticas que a representam possa ser remontada a períodos mais longínquos na história e a diferentes sociedades, é na Europa pós-revolucionária no início do século XIX que normalmente se situa o nascimento da moderna política de patrimônio cultural (CHOAY, 2001). Iniciando com uma preocupação com a preservação dos bens da Coroa e da Igreja que representassem uma história nacional através da arte, a política de patrimonialização avançou no mundo com um apetite voraz. Da patrimonialização das catedrais e grandes obras de arte à proteção do pequeno casebre representativo de uma forma peculiar de viver, a patrimonialização avançou tornando objetos a serem preservados as mais diferentes formas

7. Na cidade há um terceiro bem na Lista Tentativa para a UNESCO, o Palácio Gustavo Capanema, mas cujo processo de candidatura ainda não teve início. 
espaciais produzidas pelo homem e pela natureza. Mais recentemente, práticas culturais passam também a compor esse leque de objetos patrimonializáveis, inscritas como o patrimônio imaterial ou intangível. Música, dança, festas, passam cada vez mais a ser inscritos como patrimônios nacionais ou locais e mais países desenvolvem diferentes instrumentos para a produção de selos de patrimônio e, ao mesmo tempo, novos grupos demandam por estas rotulações. O complexo da Arca de Noé (CHOAY, 2001) que tenta salvar cada vez mais exemplares de objetos e práticas gerou aquilo que já foi chamado de inflação patrimonial (CHOAY, 2001) que tem levado à prática da patrimonialização a um inventário e acúmulo cada vez maior de objetos e práticas.

Entretanto, esse inchaço dos objetos e práticas patrimonializados que o mundo ocidental viveu não é um mero aumento do número de coisas inventariadas e protegidas. Ao longo do século XX ocorre uma verdadeira transformação no discurso legitimador da prática patrimonial. O discurso daqueles que estavam preocupados em identificar e proteger patrimônios no início do século XX é consideravelmente distinto deste início de século XXI. Por isso, no lugar de chamarmos de "expansão do campo do patrimônio", como comumente ouvimos, preferimos antes chamar de "transformação". O que ocorre não é um simples aumento de objetos inscritos, mas uma mudança significativa, talvez radical, da própria lógica patrimonial, transformando o sentido da própria prática e dos objetos patrimonializados, que vão ganhando novos valores e, portanto, tornando-se outra coisa.

No início do século XX o discurso patrimonial estava pautado por uma busca por elementos que definissem o que é a identidade nacional e que tivessem valor para toda a nação, num processo de construção de comunidades imaginadas, como identificou Benedict Anderson (2008), e legitimado sobretudo a partir da história e da arte. Dentro desse discurso, cabia aos especialistas em arte e em história identificar esses elementos que deveriam ser protegidos uma vez que representavam o espelho da nação que se queria imaginar. Com base nessa lógica, as estruturas das instituições de guarda da memória foram montadas. No caso brasileiro, como em muitos outros, cabia ao especialista a definição do que deveria ou não ser preservado. Toda a estrutura do Serviço do Patrimônio Histórico e Artístico Nacional, criada entre 1936 e 1937, foi construída a partir dessa concepção, na qual, a partir de um processo aberto por um técnico, este deveria encaminhá-lo ao conselho consultivo da instituição para que fosse tomada a decisão acerca de sua preservação e a atribuição ou não do selo de patrimônio. Aqueles que já visitaram os processos de 
tombamento de bens abertos nos primeiros anos da Instituição guardados no Arquivo Central do Iphan no Rio de Janeiro se deparam com a falta total, muitas vezes, de justificativas, como se o bem tivesse um valor em si, identificado pelo especialista e que sua indicação já bastasse para afirmar seu valor. O papel central no julgamento de especialistas é revelado também pelo convite a colaboradores ilustres, como Mário de Andrade em São Paulo e Gilberto Freyre em Pernambuco, cujas escolhas eram auto-legitimadas pelo peso de seus nomes.

Em 1949, ao tomar posse na Divisão de Estudos e Tombamentos do então DPHAN, Lúcio Costa se preocupava em formar as bases para estudos que justificassem essas escolhas e as legitimassem, uma vez que, "sem esse lastro seguro de informações os estudos tentados serão sempre tateantes e de proveito precário, porque sujeitos a desmentidos mais ou menos prontos e chocantes ou mesmo a uma completa revisão." (COSTA, 1998: 134). O que se pretendia eram escolhas baseadas em estudos e justificativas, mas que continuavam sempre na mão do técnico e de sua maneira de encarar o que deveria ser preservado, segundo as concepções de patrimônio nacional já consolidadas, que privilegiavam sobretudo, como é sabido, a arte e arquitetura colonial e barroca. Com esse fim, Lúcio Costa afirmava uma necessidade:

A criação na sede e em cada um dos distritos, de pequenas 'equipes' incumbidas unicamente de batidas sistemáticas para colheita de material de inventário, não somente nas regiões acessíveis, como também, principalmente, nas zonas de acesso difícil servidas por caminhos antigos, equipes constituídas de um fotógrafo e de um técnico habilitado - possivelmente a mesma pessoa - ambos com gosto por uma espécie de aventura que deverá ser levada a cabo sem pressa, com o espírito esportivo próprio dos caçadores e com o mesmo zelo e determinação de que dão mostra os viajantes catadores de antiguidades. (COSTA, 1998: 136)

A ideia de um "caçador", como bem mostram Motta e Rezende (1998), é aquela de alguém que parte já com objetivos e com um olhar pré-estabelecido. Só mereceria a atenção desses "aventureiros do patrimônio" aqueles objetos que se enquadrassem nas suas concepções de história e de arte e, no documento de Lúcio Costa, era necessário que a excepcionalidade do bem e seu valor nacional fossem justificados. Nesse contexto, o patrimônio 
funciona como o espelho de uma nação imaginada por um grupo, com uma função didática e civilizatória. A instituição de guarda da memória é também uma instituição de construção de um Brasil imaginado. O resultado deste Brasil imaginado por este grupo, já bastante estudado, foi sinteticamente resumido por Rubino:

O conjunto eleito revela o desejo por um país passado, com quatro séculos de história, extremamente católico, guardado por canhões, patriarcal, latifundiário, ordenado por intendências e casas de câmara e cadeia e habitado por personagens ilustres, que caminham entre pontes e chafarizes. (RUBINO, 1996, p. 98)

Os anos 1970 marcam o início de uma série de rupturas com essa maneira de ver e legitimar o patrimônio. Marcia Sant’anna (1995) já demonstrou como, no caso da preservação de sítios urbanos, há uma transformação considerável quando a cidade deixa de ser vista como um monumento e uma obra de arte completa, e passa a ser encarada como um documento. Esta transformação, reflexo também de um movimento internacional expresso na Carta de Veneza de 1964, trouxe com ela a ampliação considerável do número de centros históricos tombados. Cidades que na visão anterior encontravam dificuldades para se legitimar como patrimônio, porque não se enquadravam nos modelos de integridade arquitetônica, por exemplo, puderam ser incluídas dentro desse novo discurso. Além do arquiteto, outro profissional é chamado para atuar de maneira mais efetiva: o historiador, detentor de legitimidade para argumentar sobre os elementos da história que merecem ser lembrados.

Nos anos 1970 começam também a aparecer questionamentos ao fato de que um determinado grupo tenha autoridade para definir o que é patrimônio para toda uma coletividade. Como mostra Cecília Londres Fonseca (1998), essas perguntas começaram a aparecer de maneira indireta nos anos 1970, mas já bem diretas nos anos 1980. Foi no bojo dessa discussão que ganhou fôlego a noção de Referência Cultural. Em primeiro lugar, esta noção desloca o valor do bem, que deixa de ser intrínseco e passa a ser visto como algo atribuído, construído. Em segundo lugar, ela coloca o foco no sujeito para o qual o bem é valorizado. Assim, “o valor desses bens é sempre atribuído por sujeitos particulares, em função de determinados critérios e interesses historicamente determinados" (FONSECA, 1998: 32). Ao as- 
sumir essa ideia, tem-se uma transformação enorme em relação à forma como o patrimônio era visto e constituído pelo Estado desde os anos 1930.

No âmbito das formulações de políticas públicas no Brasil, o Centro Nacional de Referência Cultural teve um papel preponderante no desenvolvimento dessas ideias e sua fusão com o Iphan em 1979, sob a égide de Aloísio Magalhães, fez com que esse discurso fosse, aos poucos, assumindo também por esta instituição. No entanto, a entrada dessas ideias se dá de uma maneira mais forte com relação a alguns objetos que a outros. Se a ideia de Referência Cultural se pretendia muito mais como uma forma de atribuição de valor que deveria ser aplicada a toda a área de preservação cultural, é verdade que ela foi mais facilmente absorvida para se tratar as práticas do que hoje chamamos patrimônio imaterial, enquanto, na área do patrimônio material, continuam, ainda hoje, presentes noções mais acadêmicas de arte e de história. O relato de Cecília Londres Fonseca sobre essa absorção diferenciada é significativo do que estamos falando:

Nos anos 1970, em função das pesquisas que eram desenvolvidas no CNRC, onde a noção de referência cultural era corrente, e constantemente debatida, interna e externamente, costumava-se entender referência cultural como sinônimo de um tipo de bem que aquelas pesquisas priorizavam: as produções da cultural popular, os objetos híbridos compostos a partir dos produtos industriais, os fazeres e os saberes (o chamado patrimônio não-físico). (...) Se o trabalho a partir da ideia de referência cultural priorizou determinados bens - o que Aloísio Magalhães justificou em várias ocasiões em seus discursos - a questão central não era uma questão de objeto, e sim de perspectiva, de ponto de vista. (FONSECA, 1998: 33)

O episódio importante do primeiro tombamento de um terreiro de candomblé no Brasil, o Casa Branca, em Salvador, revela uma ruptura com antigas concepções associadas ao tombamento e os conflitos gerados naquele momento, quando o Conselho Consultivo da então Sphan apresentava-se dividido sobre a pertinência de se tombar "um pedaço de terra desprovido de construções que justificassem, por sua monumentalidade ou valor artístico, tal iniciativa", como mostra Gilberto Velho, relator do processo e defensor do tombamento (VELHO, 2006, p. 237). A despeito das dúvidas que tinham boa parte dos membros do conselho, não sobre a necessidade 
de preservação do terreiro, mas sobre a adequação do tombamento, este ocorreu, principalmente, por força de diferentes camadas da sociedade que geraram uma demanda e exerceram uma pressão sobre a decisão e também pela atuação de alguns conselheiros e do próprio secretário de cultura do então Ministério de Educação e Cultura.

A votação final foi muito disputada, com três votos a favor do tombamento, um pelo adiamento, duas abstenções e um voto contra, expressando o grau de dificuldade encontrado para implementar a medida. O tombamento foi comemorado com grande alegria e júbilo pela maioria do público presente, mas não podia ocultar as fortes diferenças de opinião e pontos de vista. (VELHO, 2006, p. 239)

Outros terreiros em Salvador e um em São Luis foram também tombados posteriormente, numa ação planejada para, de um lado, registrar a importância da matriz africana na cultura brasileira e, por outro, resolver problemas com a pressão que esses templos vinham recebendo e que dificultavam sua continuidade. No entanto, a aplicação do instrumento do tombamento a bens que não se enquadram em modelos mais reconhecidos resta uma discussão inacabada. A criação de um instrumento para o Registro do Patrimônio Imaterial acabou então absorvendo boa parte da pressão por reconhecimento de grupos historicamente marginalizados ou cujos bens não se enquadram nos critérios adotados.

Nos anos 2000, a política de patrimônio e a atuação do Iphan se transformam consideravelmente a partir do decreto 3.551 de 2000 que estabelece o Registro de Patrimônio Imaterial. Sintomaticamente, no mesmo ano foi lançando o Inventário Nacional de Referências Culturais - INRC - uma metodologia de inventário, consideravelmente ampla, que, partindo de uma noção antropológica de cultura, procura identificar os valores e os bens culturais significativos a um determinado grupo, prática ou território. Com o IPHAN desde então dividido internamente entre um "Departamento de Patrimônio Material" e um "Departamento do Patrimônio Imaterial", essa metodologia foi de imediato apropriada praticamente exclusivamente por este último para as ações de identificação de bens de natureza imaterial a serem registrados, enquanto para as ações com relação ao dito patrimônio material esta metodologia permanece pouco utilizada. Esse quadro é revelador das dificuldades de se trabalhar com noções mais amplas de valores, 
especialmente em se tratando de bens arquitetônicos ou materiais, e como a ideia de referência cultural passa a ser associada a bens ditos populares e de natureza imaterial. Revela também parte da dificuldade de incorporação na prática, embora o discurso seja plenamente aceito, da ideia de Referência Cultural. Essa, entretanto, não foi a única transformação no discurso do patrimônio cultural que vivenciamos nos últimos anos.

Nos anos 1990, o crescimento da problemática ambiental fez o termo desenvolvimento sustentável também ser absorvido no discurso patrimonial. Embora o discurso da prática patrimonial como preservação de valores nacionais, como expresso no decreto lei 25/37 que rege o tombamento e que também está presente no decreto $3.551 / 2000$ sobre o registro do patrimônio imaterial, jamais tenha sido abandonado, começa a ocorrer uma mudança mais significativa nas legitimações da ideia de patrimônio. Se a ideia de Referência Cultural coloca em evidência os sujeitos do patrimônio, o discurso sobre o desenvolvimento sustentável é incorporado trazendo consigo uma discussão sobre os usos e consequências da patrimonialização, trazendo consigo uma preocupação com a melhoria das condições de vida da população a partir da valorização de seus bens culturais.

Junto a este, e completando o que poderíamos chamar de tríade de transformações, outro elemento agregado ao discurso patrimonial no Brasil recentemente é a cidadania. Já em 1996 o Iphan lançava um número de sua Revista dedicada ao tema. Na apresentação desse volume, Francisco Weffort, então ministro da cultura, já afirmava:

Nosso grande desafio é outro, o de desenvolver as possibilidades democráticas da nossa cultura. A capacidade de abrangência da cultura brasileira opera, em muitos casos, como um fato de diminuição, senão da desigualdade real, pelo menos da desigualdade aparente. $\mathrm{O}$ que significa estimular os brasileiros em geral, a começar pelas maiores mais pobres da população, a desenvolver as possibilidades da expressão livre de cidadãos, enquanto cidadãos. (WEFFORT, 1996: 06)

Glauco Campello, então presidente do Iphan, assim justifica a relevância da temática assumida para esse número da revista: 
Em primeiro lugar é através da memória social, da vivência de suas marcas eruditas e do reconhecimento dos símbolos paradigmáticos do patrimônio histórico e artístico que se adquire a consciência de uma identidade cultural, pressuposto indispensável da qualidade de cidadão. Em segundo lugar, o acesso a esta memória e a estes símbolos, o reconhecimento e até mesmo a definição de seus valores e significados é um direito do cidadão. O exercício da cidadania pressupõe não só este acesso como também a participação na seleção e no modo de se apropriar desses valores. (CAMPELLO, 1996: 07)

Assim, uma mudança significativa que ocorre no discurso patrimonial diz respeito à sua relação com a mudança e a transformação. Se no Brasil dos anos 1930 e ainda nos anos 1960 a ideia de preservação patrimonial era colocada como algo oposto ao desenvolvimento e à modernização, a partir dos anos 1970 e, principalmente nos anos 1990, patrimônio e modernização podem ser vistos como complementares. Essa ideia de patrimônio associado à mudança, também está associada a uma lógica de olhar o patrimônio não a partir do passado, mas a partir das possibilidades para o futuro. É assim que Marcia Chuva (2009) aponta também para um outro aspecto desse deslocamento, quando para ela, na atualidade, a noção de patrimônio passa a ser trabalhada principalmente como memória do futuro.

Nos anos 2000 essa tríade de transformações do discurso patrimonial está plenamente absorvida: patrimônio identificado e valorado por e para as populações praticantes, como um instrumento ao mesmo tempo de preservação e de mudança social e exercido por cidadãos que devem ter suas identidades valorizadas. Na prática, no entanto, não existe uma fórmula única para a absorção desse discurso pelas políticas públicas e esses elementos estarão com maior ou menor presença segundo os contextos e objetivos. A seguir, analiso duas experiências que mostram caminhos bem distintos.

PATRIMÔNIO, CIDAdANIA E PARTICIPAÇÃo POPUlAR: Rio de JANEIro E AS Propostas PARA A UNESCO

Nessa segunda parte procuramos analisar ainda de forma preliminar, porque o processo ainda está em curso, a atuação dos setores públicos, especialmente do Iphan, diante de duas candidaturas a Patrimônio Mundial na 
cidade do Rio de Janeiro. A primeira, já inscrita na UNESCO em 2012, mas com a gestão ainda em implementação, trata-se da inscrição de partes da cidade dentro da tipologia de paisagem cultural, com título "Paisagens Cariocas: entre a montanha e o mar". A segunda, processo que se inicia em 2014, do antigo cais de chegada dos escravos, redescoberto e transformado em janela arqueológica a céu aberto pelas obras de intervenção da Zona Portuária na cidade - o Cais do Valongo. Tentamos aqui fazer uma análise desses processos e verificar de que forma esses discursos patrimoniais analisados anteriormente são incluídos, analisando a partir do processo de identificação e gestão de patrimônio, diferentes possibilidades e dificuldades para que os discursos do fazer democrático e cidadão sejam colocados em prática. Tratam-se de inscrições para o patrimônio mundial da UNESCO, cuja elaboração e gestão são coordenadas pelo Iphan. Se, por um lado, essas ações têm que obedecer a todo um conjunto de regras e prescrições impostas pela Convenção do Patrimônio Mundial e seus marcos regulatórios, as experiências são reveladoras também de como as instituições coordenadoras conseguem incorporar suas práticas. Trata-se então aqui de observar como esses discursos do patrimônio nacional já amplamente incorporados pelo órgão federal são aplicados.

No caso da inscrição das paisagens do Rio de Janeiro, processo no qual participamos da elaboração do dossiê e do plano de gestão e já analisado em outros momentos (RIBEIRO, AZEVEDO, 2010), a opção de candidatura foi realizá-la como paisagem cultural. A proposta tem início no final dos anos 1990, com o interesse do Parque Nacional da Tijuca em ser inscrito na Lista como patrimônio natural. Essa proposta é ampliada e transformada numa intenção de inscrição também de partes da cidade na categoria de bem misto, que reúne características naturais e culturais, mas sem valorizar a interação entre ambos. Após uma avaliação dos organismos consultivos da UNESCO, surge a proposta de que uma nova tentativa deveria ser feita, agora não mais como bem misto, mas como paisagem cultural. Trata-se de uma tipologia para bens culturais criada pela UNESCO em 1992, com o objetivo principal de romper com a dicotomia presente na Lista de Patrimônio Mundial entre natureza e cultura. Dessa forma, a captura do conceito ocorreu num contexto muito específico visando objetivos também bastante específicos. Isso permitiu que na prática, ao longo desses pouco mais de vinte anos em que a tipologia existe, os sítios que obtiveram sucesso tenham trabalhado com a categoria de paisagem cultural a partir de duas tradições de pensamento, já também analisada alhures: uma que cha- 
mamos de tradição paisagista e outra a que chamamos de tradição vidalina ou geográfica (RIBEIRO, 2013). De um lado, sítios associados a parque e jardins, paisagens planejadas, de outro, sítios associados a áreas rurais, populações tradicionais ou sítios arqueológicos. A forma como o conceito foi capturado, áreas que expressassem na sua forma a relação do homem com a natureza, deixa pouco espaço para inscrição de áreas de grandes cidades. Esse foi um dos problemas com os quais a candidatura do Rio de Janeiro sempre teve que lidar e os pareceres contrários à inscrição de Buenos Aires, que havia tentado pouco antes, indicavam o grau de dificuldade técnica com o qual a proposta carioca teria que lidar.

Com o objetivo de construir o dossiê de apresentação, foram constituídos três comitês: um comitê institucional, um comitê técnico e um comitê executivo. O primeiro, com uma finalidade político-institucional, era composto pelos titulares das três esferas de governo e de outras instituições, visava fundamentalmente dar legitimidade ao processo e marcar posição com relação ao fato de que seria uma proposta compartilhada por diferentes áreas do governo. O comitê técnico, composto por técnicos das diferentes secretarias de governo e de outras instituições presentes na cidade, como o Jardim Botânico, o Exército e a Marinha, tinha o papel de discutir a candidatura, reunir informações e realizar as escolhas e o enquadramento junto às normas da UNESCO. Um grupo multidisciplinar de consultores participou do processo e tinha a tarefa de, a partir das discussões com o comitê técnico, preparar o dossiê e era composto por uma arquiteta urbanista, uma arquiteta paisagista, uma antropóloga e um geógrafo, tendo também contado com uma historiadora por um período menor de tempo. Por fim, o comitê executivo tinha a tarefa de executar as ações necessárias para permitir a realização do dossiê. Quando o trabalho foi iniciado, em janeiro de 2009, uma série de ações estava prevista como complementares ao trabalho de preparação do dossiê, como campanha publicitária voltada para a população, ações de educação patrimonial, discussão com diferentes setores da sociedade, entre outras. Infelizmente, pouco ou quase nenhuma dessas ações puderam ser realizadas durante o período de preparação, por diferentes razões, entre elas a dificuldade de captação de recursos e insuficiência de pessoal.

O trabalho foi realizado fundamentalmente pelo comitê técnico, que contou com a ampla participação e apoio dos técnicos envolvidos. A narrativa escolhida, em função da opção pela inscrição como paisagem cultural, levou à declaração de valor universal excepcional a valorizar a forma como 
a cidade se relacionou com um sítio natural já especial e a série de obras realizadas sobre esse sítio. A escolha recaiu então pela forma como parte da cidade se desenvolveu entre a montanha e o mar, os parques e espaços públicos que foram projetados e implementados. Isso colocava em evidência os locais de encontro, onde boa parte da população participa, mesmo aqueles que não moram próximo a essas áreas, como a praia de Copacabana, o Parque do Flamengo, o Jardim Botânico e o Parque Nacional da Tijuca.

Durante todo o trabalho, o discurso de justificativa para a necessidade de inscrição da cidade procurou se distanciar da ideia de um título de beleza, ou de um simples aumento da atratividade turística. Mais do que o título ou um rótulo em si, foi valorizado o que ele implicaria: a necessidade de um plano de gestão. Mais do que inaugurar uma cidade dentro dos sítios inscritos como paisagem cultural, desde o início se dizia que a grande novidade para a cidade e para a própria Lista de Patrimônio Mundial seria a construção de um instrumento de gestão compartilhada a partir da ideia integradora de paisagem cultural. Um instrumento em que os diferentes gestores da área, junto com representantes da população pudessem dialogar e construir uma gestão de fato integrada. A experiência do comitê técnico em si já garantiria o embrião de um Comitê Gestor que agregasse as diferentes áreas do governo para compartilhar iniciativas e pensar ações conjuntas.

Entretanto, um fato marcante do processo de inscrição do Rio de Janeiro na Lista de Patrimônio Mundial foi a ausência de um diálogo com a população. Entendido como um trabalho eminentemente técnico, pouco ou quase nenhum diálogo houve para fora dos quadros que estavam trabalhando no processo, fato que se reflete na constatação de que hoje boa parte da população da cidade sequer sabe do título e muito menos para que este serve. Críticas com relação à inclusão de determinadas áreas, já historicamente privilegiadas pelo poder público da Zona Sul da cidade, em detrimento de outras menos privilegiadas também são uma constante. Esta última crítica tem como resposta o fato de a inscrição incluir na verdade as grandes áreas públicas da cidade, os locais de encontro, mas também o fato de que o que o mais importante seria a obrigação da construção de instrumentos de gestão que incorporariam a cidade como um todo. Já a primeira, a solução para a incorporação de instrumentos de diálogo com a população poderia vir com a gestão.

Em função do ineditismo da proposta, a inscrição foi acatada pelo Comitê do Patrimônio Mundial em sua reunião anual de 2012 sem que o plano de 
gestão para o sítio estivesse concluído, tendo sido dado um prazo de dois anos para que este fosse elaborado e entregue. O comitê técnico continuou suas reuniões ao longo desse período, ainda que com alguma irregularidade, e em fevereiro de 2014 o documento foi entregue. Além de apontar um diagnóstico da situação, e instrumentos de monitoramento, o elemento central do sistema de gestão apontado é o Comitê Gestor da Paisagem Cultural do Rio de Janeiro, pensado como órgão consultivo e local de articulação de políticas públicas da cidade.

O Comitê Gestor que vem sendo estruturado e encontra-se no momento de ser sancionado para ser colocado em efetividade na sua nova estrutura é uma derivação do comitê técnico. Comandado pelo superintendente do Iphan no Rio de Janeiro, reúne os responsáveis pela gestão de diferentes setores de governo e das instituições que funcionam dentro da área inscrita ou de sua zona de amortecimento. Como participação da sociedade civil, a proposta inicial reunia apenas setores também ligados aos técnicos, como o Conselho de Arquitetura e Urbanismo e o Instituto dos Arquitetos do Brasil. Assim, inicialmente, o comitê gestor herdaria uma estrutura eminentemente técnica e fechada como havia sido a candidatura.

Entretanto esse panorama parece se alterar, ainda que timidamente, no momento em que Federação das Associações de Moradores da cidade do Rio de Janeiro envia carta à presidência do Iphan solicitando a participação no Comitê Gestor. Na reunião em que a carta foi apresentada aos membros do comitê, uma discussão se seguiu, com alguns questionando a legitimidade da federação falar em nome das associações, mas finalmente sua inclusão foi aceita. O episódio é revelador de uma movimentação no sentido "de baixo para cima", de alguns setores da sociedade organizada para sua inclusão neste que era o objetivo central da inscrição da cidade, isto é, a ideia de gestão compartilhada. Revela também o entendimento de alguns setores que uma gestão compartilhada para que possa ser legitima precisa criar canais de participação da sociedade. Talvez, esteja sendo plantada aí, de fato a verdadeira inovação que a inscrição do Rio de Janeiro pode oferecer. Entretanto, seu sucesso dependerá da forma como o processo será encaminhado nos próximos anos, consolidando-se ou não. Várias questões se colocam sobre o futuro de um instrumento que pode ser inovador e inclusivo ou se tornar só uma figura sem importância e apenas para cumprir exigências da UNESCO. O futuro e as próximas ações dirão. 
Este panorama é bastante distinto daquele que foi construído para a candidatura do Cais do Valongo. Há muito tempo que a região portuária do Rio de Janeiro, notadamente a área compreendida entre a Praça Mauá e os bairros da Saúde, Gamboa e Santo Cristo é apontada como referência para a história da cultura afro-descendente na cidade e no país. Pequena África, berço do samba, território quilombola, muitas são as referências já bastante fortes em função da história do local, de ter sido principal porto de chegada de africanos no Brasil e onde muitos foram morar, sobretudo após a abolição da escravidão. Claramente, essas representações da área relacionadas a um patrimônio afrodescendente não se fazem sem conflito com outras representações para aquele espaço, feitas por outros grupos, como demonstra Guimarães (2014).

Entretanto, esse aspecto chama mais a atenção do poder público principalmente a partir das grandes obras de intervenção na região, que se caracterizam por um mega projeto de "revitalização" ou "requalificação", como costuma ser chamado por alguns setores, onde além da derrubada da grande via elevada que cortava a área e por onde uma parte expressiva do tráfego da cidade passava, também constam a construção de grandes equipamentos de lazer e cultura, como dois museus e o aquário da cidade, incentivos à construção de grandes edifícios corporativos que em algumas áreas podem alcançar quarenta andares, a renovação das áreas públicas e do sistema de transporte e a atração de população, prevista inicialmente para passar dos atuais vinte mil habitantes, para cem mil habitantes até 2020. Trata-se também de um grande negócio imobiliário de valorização e revenda do solo urbano de uma área central da cidade com grande potencial construtivo.

Na verdade, projetos para a Zona Portuária, vista como área decadente e problemática, remontam a pelo menos aos anos 1980, mas que nos seus estudos e classificações ignoravam em grande parte a narrativa da cultura negra da região, privilegiando outros discursos como aquele que associa o Morro da Conceição a um espaço ligado a portugueses e espanhóis. Alguns setores da população começaram a reivindicar que a narrativa da cultura de matriz africana fosse reconhecida naquela área, como estratégia política e de reforço de identidades. Assim, "A pequena África emergiu como reação ao esquecimento dos espaços, patrimônios e memórias negras e do candomblé no projeto de 'revitalização urbana' do Morro da Conceição e de toda a Zona Portuária (RODRIGUES, 2014: 53). A construção de uma narrativa da memória negra e de reivindicação de espaços para a celebração dessa memória aparece assim como uma estratégia de alguns grupos, reivindicando sua identidade 
e, a partir dela, demandando empoderamento que deveria se materializar nos discursos sobre a região e no próprio espaço, algumas vezes motivados por disputas de propriedade de terrenos. Não que não houvesse já algum reconhecimento público dessa narrativa, fato que pode ser comprovado pelo tombamento da Pedra do Sal pelo Inepac, órgão estadual de patrimônio, em 1984. No entanto, os projetos de intervenção até então pouco ou nada incluíam essa ideia, trabalhando a área em sua maior parte como uma zona degradada, abandonada e carente de projetos de renovação, quase uma tábula rasa para grandes projetos de urbanismo imporem uma nova ordem, moderna, contemporânea, que apontasse para um "novo Rio de Janeiro", cidade mundial. Foi em função disso que movimentos de resistência se organizaram e que a cultura e o patrimônio foram incorporados num discurso mobilizador e legitimador de suas demandas.

Essa discussão ganha força quando, em 2010, aproveitando as escavações para a instalação de infraestrutura associada às intervenções do projeto Porto Maravilha, foi feito por parte do setor de arqueologia do Museu Nacional um pedido de escavação arqueológica para que se buscasse o Cais da Imperatriz e o Cais do Valongo. Já se acreditava que estes estivessem na área, uma vez que um marco indicativo da localização do cais por onde havia chegado a Imperatriz Tereza Cristina havia sido colocado durante as reformas de Pereira Passos no início do século XX que aterraram toda a região e vários mapas e documentos do século XIX também indicavam sua localização. Após mais de 150 anos de tentativas de apagamento de sua memória, o cais por onde se acredita ter chegado o maior número de africanos no continente americano seria buscado.

As escavações revelaram o Cais do Valongo sessenta centímetros abaixo do Cais da Imperatriz, primeira ação de apagamento dessa história, e tem início uma discussão para que esse não seja novamente enterrado após o término das obras. A decisão tomada de mudar o projeto original daquela avenida e construir ali um parque arqueológico a céu aberto foi tomada após a pressão, tanto dos arqueólogos, quando de alguns setores do movimento negro. Ele provocou também a necessidade de mostrar que o cais não estava isolado no espaço, mas que fazia parte de um complexo associado à escravidão que tomava boa parte daquela área, como a área de covas rasas onde os negros mortos e moribundos que chegavam eram jogados, conhecida como Cemitério dos Pretos Novos, o lazareto e o mercado de engorda e venda de escravos. As tentativas de construir ali um lugar de celebração da cultura negra tem início e são incorporadas pelo poder público, 
transformando aquela área num dos vetores culturais do projeto Porto Maravilha, que não havia sido planejado inicialmente. Dessa forma, a partir de uma demanda de alguns grupos e da identificação dos potenciais para melhor caracterizar a área de intervenção do Porto Maravilha, o discurso do patrimônio negro foi incorporado pelo poder público municipal.

Em 2011, por Decreto Municipal foi criado o Circuito Histórico e Arqueológico de Celebração da Herança Africana e o Grupo Curatorial do projeto urbanístico, arquitetônico e museológico do circuito. Além de representante da então subsecretaria de patrimônio e da CDURP, empresa municipal encarregada das obras do porto, uma série de representantes do movimento negro são os nomeados para esta comissão. Foi criado assim um circuito da herança africana na região portuária que inclui diferentes pontos e aspectos dessa herança e atende aos interesses de muitos desses grupos em dar visibilidade e marcar o espaço com a sua atuação.

É nesse contexto que se inicia em 2013 uma discussão sobre a inscrição do Cais do Valongo como patrimônio mundial. Em 2014 a área é e aceita e incluída pela UNESCO na Lista Indicativa do Brasil, isto é, a lista dos sítios que podem apresentar candidaturas ao patrimônio mundial. Um aspecto importante é que no mesmo momento em que se começa a construir um dossiê, é organizado e empossado um conselho consultivo da candidatura, reunindo diferentes grupos interessados, visando discutir com os técnicos os caminhos e as escolhas. No momento em que este texto é finalizado, os trabalhos começam ${ }^{8}$.

O que é interessante nessas duas inscrições é que, se a candidatura do Rio de Janeiro teve uma motivação eminentemente técnica e voltada para a gestão, a candidatura do Cais do Valongo tem um papel de empoderamento de identidades, com o título e a maneira como ele é construído desempenhando um papel central. Se na paisagem do Rio de Janeiro todo o processo se dá "de cima para baixo", no caso do Valongo há uma demanda inicial criada por grupos e que se apropriam da candidatura desde o início. Entretanto, a ausência da população na discussão sobre a paisagem do Rio desde o início faz dela uma inscrição menos legítima? Não acreditamos. Ambas estão envoltas em lógicas de discursos patrimoniais bastante distintas, enquanto uma é construída a partir da ideia da gestão, a outra é construída a partir da ideia de reforço e construção de identidades.

8. O sítio foi inscrito na Lista de Patrimônio Mundial em 2017. 
O processo de patrimonialização oficial, isto é, o ato de tornar patrimônio, corresponde a um investimento de um caráter de distinção à coisa patrimonializada. A coisa, seja ela material ou imaterial, uma vez tendo passado por esse processo, passa a funcionar dentro de uma lógica patrimonial. Muito tem se falado sobre a mercatilização do patrimônio e de uma lógica de ordem econômica que estaria motivando em grande parte esse processo, uma vez que o selo de patrimonialização agregaria também valor de mercado ao objeto patrimonializado. Não sejamos aqui tão reducionistas ao pensar que essa é a única razão da busca e ampliação da dinâmica patrimonial nos dias de hoje, mas também não devemos negar sua expressividade dentro do processo e que este é um dos elementos que devem ser colocados em cena nas análises. Entretanto, nos interessa aqui sua vertente política e sua relação com a prática da cidadania ativa. Longe de guardar um significado único, o que consideramos como patrimônio se transformou com o tempo. Há um deslocamento conceitual significativo e, muito mais do que uma ampliação, o que ocorre é um acúmulo diferenciado de perspectivas, que são chamadas a operar em contextos diferenciados.

Embora o reconhecimento pelo Estado seja o ato de investidura oficial desse caráter distintivo, ele só passa a funcionar na prática se reconhecido por diferentes setores da sociedade. No caso brasileiro, existem vários casos de tombamentos que "não pegaram", seja pela falta de definição daquilo que se estava tombando, seja pela falta de fiscalização, seja simplesmente pela total ignorância por parte da sociedade de que se trata de um bem tombado, ou todos esses fatores conjugados, como no caso do tombamento dos morros do Rio de Janeiro, feito em 1938, que dizia simplesmente que estavam tombados todos os morros do Distrito Federal.

A inscrição da paisagem cultural do Rio de Janeiro não contou com a participação da população. Entre as razões apontadas para isso estava o caráter eminentemente técnico da proposta e a necessidade de enquadramento dentro das normas rígidas da UNESCO e de uma candidatura que se colocava como um desafio a essas regras, além claro, das dificuldades institucionais para a realização das demais atividades previstas, dentro do prazo exíguo que se tinha para preparação de toda a documentação. Nesse sentido, o papel do grupo técnico, "capaz" de identificar o que é merecedor do título de patrimônio, sem um diálogo construído com os legítimos mo- 
radores da área parece bastante claro. A ideia de referência cultural é usada apenas no sentido de aproveitar um sentido antropológico de cultura, sem, no entanto, ouvir diretamente as pessoas implicadas, mas a partir de uma seleção realizada por um grupo de especialistas, buscando um determinado enquadramento.

Sem dúvida alguma, no caso da paisagem cultural do Rio de Janeiro, trata-se de uma candidatura "de cima para baixo", isto é, construída por um grupo restrito que procura realçar valores consagrados da cidade e reafirmá-los, mas sem mecanismos de diálogo maiores com a população no momento de sua elaboração. Entretanto, ao colocar o título como mera formalidade para a obrigação da criação de um comitê gestor, o papel principal é deslocado do título, da identificação e da delimitação, para ressaltar o papel da gestão. A função primordial do título e motivo dele ser buscado seria a promoção de um desenvolvimento sustentável, no qual os cidadãos poderiam participar. Assim, a tarefa de inclusão de diferentes setores da sociedade e de construção de uma representação legítima dentro de mecanismos de gestão torna-se o principal alvo e é vista como uma solução que anularia a ausência de uma discussão mais ampla no momento da inscrição. $O$ fato de o processo de inscrição ter sido feito de "cima para baixo" não anula a possibilidade de esta inscrição se tornar um instrumento de uso verdadeiramente democrático e constituidor de cidadanias, entretanto, isto ainda permanece como devir.

Já a candidatura do Cais do Valongo se insere em um discurso patrimonial totalmente distinto, no qual a valorização de identidades através do espaço, ou, para usar a expressão consagrada por Pierre Nora, de lugares de memória, tem o papel central e que é rapidamente acolhido pelo poder público, uma vez que sua adequação aos projetos de transformação daquela área, além da valorização turística, são identificados por seus responsáveis. Construir um discurso pautado na vontade popular aqui é uma prerrogativa fundamental e incorporada no processo desde o início pelos gestores.

As "razões do patrimônio", isto é, a maneira como o discurso patrimonial é trabalhada, são distintas e, portanto, incorporam diferentes elementos, mas ambos, se querem legitimidade, ao longo do percurso precisam ser acatados e aceitos pela população, ao preço de se tornarem meros elementos decorativos não se sabe bem para quem. 
ANDERSON, B. Comunidades Imaginadas. Reflexões sobre a origem e a difusão do nacionalismo. São Paulo: Cia das Letras, 2008.

BRASIL, Instituto do Patrimônio Histórico e Artístico Nacional (IPHAN). Inventário Nacional de Referências Culturais. Manual de Aplicação. Brasília: Iphan/Minc, 2000.

CAMPELLO, G. Apresentação. In. Revista do Patrimônio Histórico e Artístico Nacional, n. 24, 1996, p. 07.

CASTRO, I. E. A democracia como um problema para a geografia: o fundamento territorial da política. In: CASTRO, I. E.; RODRIGUES, J. N.; RIBEIRO, R. W. (orgs.). Espaços da democracia: para a agenda da geografia contemporânea. Rio de Janeiro: Bertrand Brasil, 2013, p. 23-56.

CHOAY, F. A alegoria do patrimônio. São Paulo: Estação Liberdade, Unesp, 2001.

COSTA, Lúcio. Plano de trabalho para a Divisão de Estudos e Tombamentos da DPHAN [1949]. In: MOTTA, L.; SILVA, M. B. R. (orgs.). Inventários de Identificação. Rio de Janeiro: Iphan, 1998, p. 133-140.

CHUVA, M. Os arquitetos da memória: sociogênese das práticas de preservação do patrimônio cultural no Brasil (anos 1930-1940). Rio de Janeiro: EdUFRJ, 2009.

FONSECA, M. C. L. A noção de referência cultural nos trabalhos de inventário. In: MOTTA, L.; SILVA, M. B. R. (orgs.). Inventários de Identificação. Rio de Janeiro: Iphan, 1998, p. 27-40.

GUIMARÃES, Roberta Sampaio. A utopia da Pequena África. Projetos urbanísticos, patrimônios e conflitos na Zona Portuária Carioca. Rio de Janeiro: Ed. FGV, 2014.

MOTTA, L.; SILVA, M. B. R. (orgs.). Inventários de Identificação. Rio de Janeiro: Iphan, 1998.

RIBEIRO, R. W. Nature et culture dans la liste du patrimoine mondial: l'expérience de Rio de Janeiro. Vertig0 - La revue électronique en scienses de l'environnement, v. 16, p. 01, 2013. 
RIBEIRO, R. W.; AZEVEDO, D. A. Paisagem Cultural e Patrimônio Mundial no Rio de Janeiro: Caminhos e desafios para o reconhecimento. Colóquio Ibero Americano Sobre Paisagem Cultural, Patrimõnio E Projeto, 1, 2010, Belo Horizonte. Anais. Belo Horizonte: UFMG, 2010.

RUBINO, S. O mapa do Brasil passado. Revista do Patrimônio Histórico e Artístico Nacional. 24, 1996, p. 97-105.

SANT'ANNA, M. Da cidade-monumento à cidade-documento: a trajetória da norma de preservação de áreas urbanas no Brasil (1937-1990). Salvador: UFBA,1995. Dissertação (Mestrado em Arquitetura e Urbanismo), Faculdade de Arquitetura, Universidade Federal da Bahia, 1995.

SEN, A. A idéia de justiça. São Paulo: Companhia das Letras: 2011.

STARLING, M. B. L. Patrimônio, participação local e democracia: o papel dos conselhos municipais de patrimônio cultural de Minas Gerais. Políticas Culturais em Revista, 1 (2), p. 140-156, 2009.

VELHO, G. Patrimônio, negociação e conflito. Mana. 2006, vol.12, n.1, pp. 237-248. 